\title{
Emil J. Freireich: Legend in cancer research (March 16, 1927-February 1, 2021)
}

\author{
Hagop Kantarjian $\mathbb{1 0}^{1}$
}

Received: 1 March 2021 / Revised: 3 March 2021 / Accepted: 24 March 2021 / Published online: 13 May 2021

(c) The Author(s), under exclusive licence to Springer Nature Limited 2021

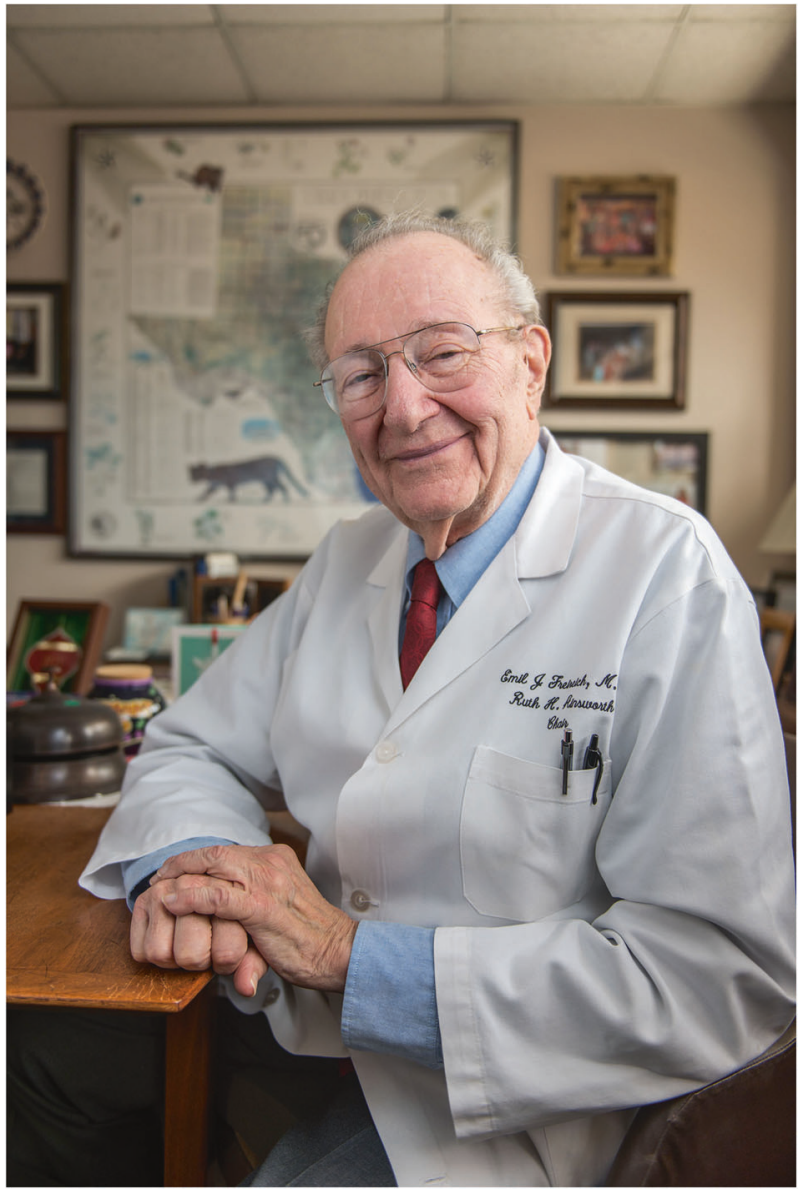

This article is co-published in the journals Bone Marrow

Transplantation and Leukemia https://doi.org/10.1038/s41409-02101284-z or https://doi.org/10.1038/s41375-021-01215-3.

Hagop Kantarjian

hkantarjian@mdanderson.org

1 https://www.nature.com/BoneMarrowTransplant/
Emil J. Freireich was a trailblazing scientist and the founding father of modern cancer research and care. To many of us who knew him well, he was much more: an idol and hero, a daily inspirational role model, a mentor and often a third parent. As he did for hundreds of us, Freireich brought me from a distant country to the United States when I was a 24-year-old medical student for a 4-month elective rotation, then in 1981 as a fellow. He took us under his wing at the University of Texas MD Anderson Cancer Center, provided us with endless opportunities, and helped us become, for better or for worse, who we are today.

President Obama's book title "The Audacity of Hope" describes the two salient characteristics that define the arc of his life and career.

Freireich was first and foremost infinitely hopeful and optimistic. He said: "Humans cannot live without hope. Hopelessness is the greatest trauma a person has to suffer." He knew this firsthand, having been born in 1927 under merciless conditions in Chicago, and having lost his father when he was 2. In his 1997 oral history (preserved at the National Cancer Institute [NCI]), he said, "People born in that era are a special brand of people because they lived through one of the greatest economic dislocations in the history of our species - the Great Depression of 1929.... There was no work, no jobs, no money, and no food...we all grew up believing that the whole world was this jungle we were in...worried about food, shelter, and safety. We used to get beat up, we used to get robbed, we used to steal, we were hungry, we did all kinds of things." But Freireich overcame these obstacles to become one of the greatest pioneers in cancer research. Where others saw insurmountable difficulties (the incurable cancer), he saw an opportunity to develop the first curative regimens in childhood leukemia, the paradigm that would lead to the cure of many other cancers.

He had also unlimited audacity. He dared to challenge the then established dogmas of medicine, to go against powerful currents of knowledge, and to envision unexplored opportunities others were afraid to consider. $\mathrm{He}$ 
established the causal association between low platelet counts and bleeding and then noted the reduction in bleeding with fresh blood transfusions. But when he presented the findings at a scientific meeting, the preeminent hematologist of the time commented that he had repeated the experiments in his laboratory and could not reproduce the findings, to which Freireich replied, "My laboratory does it better." As the French say: "Il n'etait pas comme il faut." Freireich and colleague Kenneth McCredie enjoyed and embraced this image of apartness, the rogue cowboys from Texas, dressing often in the 1970s in ten-gallon hats and cowboy boots, which added literally another foot to their already impressive six-foot-plus frames and made them both even larger than "larger than life."

When cancer research was still in its infancy in the 1950 s-1960s, there were no guiding principles or "commandments," and established figures borrowed from other disciplines. So Freireich created his own, "Freireich's laws." After observing children with leukemia facing terrible deaths on the NCI wards, he treated them with two-, then three-, and then four-drug chemotherapy combinations. The reaction of the medical establishment was anger and a severe backlash. Although they chastised him, ridiculed his work, questioned the veracity of his publications and called him a murderer, Freireich persevered when others might have folded. The naysayers reminded him of one of the most repeated mantras in medicine, the quote attributed to Hippocrates: "Primum non nocere" (first do no harm). He should let these children die in peace and with dignity, they said. Freireich countered with his own edict, Freireich's Law No. 5 (the Physician's Creed): "Primum non nocere fails to do the possible and the necessary. The physician's admonition must clearly be: Do what can possibly be done and, perhaps more important, do that which is necessary."

Freireich was a fighter and survivor. He emerged from destitution to become a Promethean pioneer in cancer research who gave hope to those fighting what was once considered a hopeless disease. Although the idea of going to college had never crossed his mind, he was inspired by his high school physics teacher to pursue a college education and received his bachelor's degree from the University of Illinois-Champaign, waiting tables and a variety of other odd jobs to pay for tuition. He then attended the University of Illinois College of Medicine at Chicago, where he earned his medical degree in 1949 at age 22. With his sights set on a career as a family doctor, Freireich completed his training in internal medicine at Cook County Hospital and Presbyterian Hospital. But after accepting a fellowship in hematology at Massachusetts Memorial Hospital in Boston to study anemia, he discovered two new loves: blood disorders and a beautiful nurse named Haroldine Lee Cunningham, whom he married in 1953. His career in cancer research began in1955, when was hired by the NCI as a senior investigator and director of the leukemia program to study childhood acute leukemia.

"Leukemia at that time was a horrible illness-a death sentence," Freireich said in a 2015 interview. "Most children lived only 8 weeks after being diagnosed." After discovering the benefit of platelet transfusions in reducing bleeding, he collaborated with IBM engineer George Judson to design the first-ever continuous-flow blood cell separator that extracted platelets from whole blood. He later developed the multidrug regimen that paved the way for the cure of most children with acute lymphocytic leukemia (ALL).

He was among the first generation of cancer pioneers at the NCI-Charles Gordon Zubrod, James Holland, and Emil "Tom" Frei III. Freireich, who went by "Jay," described his first encounter with Frei when he was directed to his own office and saw "Emil Frei III" on the door: "Damn! It's...typical government stuff-can't even spell my name! So, I walk into this room. And here's this tall, skinny guy with no hair. So I said, 'You're in my office.' He said, 'Are you kidding? This is my office! What's your name?"' It turns out that Freireich's office was next door, and this is how Frei and Freireich met for the first time. "There was Emil Frei IIIand Emil Freireich," he marveled. "And we have been friends from April 10, 1955 to this day - friends and intellectual colleagues... and we really fought the wars there in the Clinical Center." Freireich even named his firstborn son Tom.

Describing the tension around his work at the NCI, Freireich related that Frei saved him from being fired at least 3 times. Vincent DeVita, who joined the NCI as a clinical associate in 1963, was inspired by Freireich's work and developed the well-known curative MOPP regimen in Hodgkin's disease. He recalled that many of the clinical associates "had been warned by their professors not to get too close to Freireich, saying that [the NCI] was a good place to go to stay out of Vietnam, but stay away from Freireich." Freireich's radical research and groundbreaking discoveries, combined with an intimidating personality and an unshakable belief in the certain success of his endeavors must have generated some resentment.

After a 10-year stint at the NCI, Freireich (together with Frei) moved in 1965 to Houston, his real home, where he spent the next 55 years. They were recruited to MD Anderson, a then-burgeoning "Tumor and Research Institute" propped up by oil money and focused on surgery and radiation therapy to treat cancer. Freireich and Frei created the Department of Developmental Therapeutics (DT), a new entity dedicated to developing drugs and medical treatments for cancer. Freireich was a force of nature who exuded charisma, projected optimism in abundance, stared down the devil, and promised hope to patients with leukemia, often delivering on the promise). Over the next 15 years, he 
attracted hundreds of cancer researchers from all over the world who shared his research vision and determination to cure cancer. At its peak in 1975-79, DT was the largest single conglomeration dedicated to cancer research, akin to a "Grand Bazaar" where an exceptionally eclectic (and occasionally eccentric) group of people discussed, argued, negotiated, debated and conceived exciting ideas that resulted in major advances in cancer. Many of the early chemotherapy drugs such as cytarabine, Adriamycin, and cisplatin were developed during this period, and these became building blocks for curative combinations in cancer: CHOP in lymphoma; 5-fluorouracil-Adriamycincyclophosphamide (FAC) in breast cancer; bleomycinvelban (and the later addition of cisplatin by Lawrence Einhorn, a DT fellow in 1973, who is credited with the cure of testicular cancer); and others. Freireich's legacy in DT is less spoken of: He educated hundreds of oncologists, many of whom went back to create their own cancer research and care institutes in distant geographies, establishing their own legacies and helping hundreds of thousands of patients with cancer.

An important contribution of Freireich emerged from a collaboration with Gerald Bodey, who had described the association between neutropenia and infections. Bodey and Freireich then proceeded to develop the concept of using empiric antibiotics in the setting of fever and neutropenia (without waiting for positive cultures). This, along with platelet transfusions, reduced significantly the two most common causes of death during cancer therapy, and allowed the broad expansion of intensive chemotherapy in hematologic and solid malignancies, and the use of stem cell transplantation.

Freireich and the NCI group conducted some of the first randomized trials in cancer. But, in the early days of cancer research, the control arm was invariably associated with very poor results. Freireich soon formed strong opinions about this form of research, realizing that, based on cumulative knowledge, the investigational treatment would often offer a better option than the placebo or standard of care arm, and would become the new standard of care. In a heated argument when one of us was defending the value of a randomized trial in which the control arm was expected to produce an estimated 1-year survival of $<10 \%$, Freireich said: "This is like a half-Tuskegee experiment. It would be different if the control arm was curing even $30 \%$; but this?" Then: "A treatment that works in leukemia will hit you like a Muhammad Ali right straight punch. If you do not realize it, it is because you are already knocked out." In Freireich's law No. 1 (Clinical Investigator's Creed), he said: "The primary beneficiary of clinical research is the patient participating in that research." He then collaborated with Gehan (who created the first survival curves in cancer), Peter Thall and Elihu Estey to develop and adopt methodologies that allowed the recognition of a treatment benefit without resorting to randomized trials: rigorously matched historical controls, multivariate analysis, Bayesian statistics and designs, etc. As a corollary to the clinical investigator's creed, Freireich rejected the notion that a phase 1 trial aims only to define a treatment toxicity (as is traditionally accepted), stating that it must evaluate the benefit as well. We have today several agents approved based on phase 1 trial efficacy. He also did not like the term of "experimental therapy" (benefit only to the experimenter) preferring the use of "investigational therapy" (benefit to the patient first and then to the investigator). In Freireich's law No. 6 he said: "The best patient care is clinical research".

Freireich seemed to irritate people at times just because of his success, but as they say, "Fortune favors the bold." He started the use of acronyms in cancer and shared, for the sake of humor, this review of the paper on POMP in ALL submitted to the Blood journal in 1965: "The treatment they propose is a drastic one.... There is also an irritating quality to the writing. The use of acronyms for drug combinations is amusing but seems an excessive effort for the results they report. POMP, BIKE, and VAMP are going to have the acceptance of RADAR, and LASER or WAVES, ...they exhibit a devious talent inappropriate in a scientific report." We certainly have done worse with acronyms today.

I joined the Leukemia program as an attending in 1983 and spent the next 3-4 years rounding almost every other month with Freireich, McCredie, Michael Keating, and Estey. For me, these were the most formative, happy, fun times. Freireich was a great raconteur, who infused his teachings with humor. He emphasized that all knowledge is contemporary and transient, that medical knowledge doubles every 2 years, and that most of what is accepted as true today will soon become obsolete. In order to continue to create and gain knowledge, one needs to continuously question the perceived standards of care, and to challenge concepts of leukemia care and research.

Freireich's personality, strong opinions and occasional harsh counsel quickly divided the world around him into two groups: those who idolized him unconditionally and those who disliked him unconditionally. He inspired the imagination of the former and excited the curiosity of the latter, who, despite their early resentment, came to admire him. Some tell stories of difficult encounters with Freireich, but he could also manifest unlimited kindness. He and I often had strong opinions on leukemia research in the first two decades. Later, he would just chuckle when, trying to mimic a younger Freireich, I would heatedly discuss some controversial leukemia research proposal (even telling me once to "tone it down a bit"). Yet, in my 43 years of knowing Freireich, he never once showed anything but support, love and respect. 
Freireich often sacrificed political capital for the sake of scientific truth. This likely cost him his due recognition because he was viewed as an outsider and iconoclast. He did not receive any of the American Society of Hematology awards, was not inducted into the National Academy of Sciences or Medicine, and never entered the pantheon of the Nobels. In this he was in good company: Mahatma Gandhi (Peace); Stephen Hawking (Physics)' Jonas Salk and Rosalind Franklin (Medicine); and, in my favorite category, literature: Leo Tolstoy, Georges Brassens and Jacques Brel (best poets in any language), Philip Roth, Graham Greene, Amos Oz, John Le Carre, and (not yet) Salman Rushdie and Hanan al-Shaykh. As Freireich said: "If you aim to get credit for progress, you will never make progress."

Freireich's friend and colleague Robert Gale wrote on the parallels in the lives of Freireich and Baruch (de) Spinoza, the 17 th century Dutch philosopher. He said both were geniuses in their respective disciplines and yet outsiders to the establishment. And that Hegel mused that "Spinoza is made a testing-point in modern philosophy, so it may really be said: You are either a Spinozist or not a philosopher at all". Should we then also say, "You are either a Freireichist or not an oncologist at all?" Spinoza is referred to as the prince of philosophers. Such is the reputation of Freireich, a prince among oncologists.

Freireich dedicated more than half a century of his life to MD Anderson and spread magic, happiness and passion for scientific discovery to all those he encountered. He passed away in February 2021, surrounded by his MD Anderson family and cared for by his colleagues. Although we grieve his loss, he will forever be remembered as a compassionate and fearless scientist who fought for his patients and revolutionized cancer research. In remembering Freireich, we hope we have not downplayed his flaws. But we also hope that we have made clear his greatness. 